\title{
Interfacial Chemical Effects of Amorphous Zinc Oxide/Graphene
}

\author{
Zhuo Zhao ${ }^{1,2,+} \mathbb{D}$, Fang Fang ${ }^{2,+}$, Junsheng $W u^{1,2} \mathbb{D}$, Xinru Tong ${ }^{3}$, Yanwen Zhou ${ }^{1,2, *}$, Zhe Lv ${ }^{1,2}$, Jian Wang 4 \\ and David Sawtell $5, *$ (i)
}

1 School of Chemical Engineering, University of Science and Technology Liaoning, Anshan 114051, China; zhaozhuo@ustl.edu.cn (Z.Z.); justinwu@yeah.net (J.W.); lz198705222@126.com (Z.L.)

2 Research Institute of Surface Engineering, University of Science and Technology Liaoning, Anshan 114051, China; aiyu912@163.com

3 Ansteel Iron and Steel Research Institute, Anshan 114009, China; 15566262831@163.com

4 College of Science, University of Science and Technology Liaoning, Anshan 114051, China; jwang@ustl.edu.cn

5 Surface Engineering Group, Manchester Metropolitan University, Manchester M15GD, UK

* Correspondence: zhouyanwen1966@163.com (Y.Z.); d.sawtell@mmu.ac.uk (D.S.)

+ Zhuo Zhao and Fang Fang equally contributed to this paper.

Citation: Zhao, Z.; Fang, F.; Wu, J.; Tong, X.; Zhou, Y.; Lv, Z.; Wang, J.; Sawtell, D. Interfacial Chemical Effects of Amorphous Zinc Oxide/Graphene. Materials 2021, 14 , 2481. https://doi.org/10.3390/ ma14102481

Academic Editor: Alexander N. Obraztsov

Received: 5 April 2021

Accepted: 10 May 2021

Published: 11 May 2021

Publisher's Note: MDPI stays neutral with regard to jurisdictional claims in published maps and institutional affiliations.

Copyright: (c) 2021 by the authors. Licensee MDPI, Basel, Switzerland. This article is an open access article distributed under the terms and conditions of the Creative Commons Attribution (CC BY) license (https:// creativecommons.org/licenses/by/ $4.0 /)$.

\begin{abstract}
Research on the preparation and performance of graphene composite materials has become a hotspot due to the excellent electrical and mechanical properties of graphene. Among such composite materials, zinc oxide/graphene ( $\mathrm{ZnO} /$ graphene) composite films are an active research topic. Therefore, in this study, we used the vacuum thermal evaporation technique at different evaporation voltages to fabricate an amorphous $\mathrm{ZnO} /$ graphene composite film on a flexible polyethylene terephthalate (PET). The amorphous $\mathrm{ZnO} /$ graphene composite film inherited the great transparency of the graphene within the visible spectrum. Moreover, its electrical properties were better than those of pure $\mathrm{ZnO}$ but less than those of graphene, which is not consistent with the original theoretical research (wherein the performance of the composite films was better than that of $\mathrm{ZnO}$ film and slightly lower than that of graphene). For example, the bulk free charge carrier concentrations of the composite films $\left(0.13,1.36\right.$, and $0.47 \times 10^{18} \mathrm{~cm}^{-3}$ corresponding to composite films with thicknesses of 40,75 , and $160 \mathrm{~nm})$ were remarkably lower than that of the bare graphene $\left(964 \times 10^{18} \mathrm{~cm}^{-3}\right)$ and better than that of the $\mathrm{ZnO}\left(0.10 \times 10^{18} \mathrm{~cm}^{-3}\right)$. The underlying mechanism for the abnormal electrical performance was further demonstrated by X-ray photoelectron spectroscopy (XPS) detection and first-principles calculations. The analysis found that chemical bonds were formed between the oxide (O) of amorphous $\mathrm{ZnO}$ and the carbon $(\mathrm{C})$ of graphene and that the transfer of the $\pi$ electrons was restricted by $\mathrm{C}=\mathrm{O}$ and $\mathrm{C}-\mathrm{O}-\mathrm{C}$ bonds. Given the above, this study further clarifies the mechanism affecting the photoelectric properties of amorphous composite films.
\end{abstract}

Keywords: amorphous; composite film; photoelectric properties; chemical bonds

\section{Introduction}

Zinc oxide $(\mathrm{ZnO})$ films underpin the development of solar cells [1,2], gas sensor applications [3-5], displays [6-8], and optoelectronic components [9-11]; moreover, they can function both as electrodes and as front windows owing to their semiconducting properties and wide band gap. Most of the current studies focus on crystalline $\mathrm{ZnO}$ films prepared on a glass substrate. To expand the application field, flexible substrates are replacing glass. Graphene as a flexible substrate, which has a special 2D structure and extraordinary mechanical [12-14], optical [15-17], and electrical properties [18,19], is a good solution for a wider range of applications, such as light-emitting diodes [20], flexible displays [21], and flexible solar energy [22], due to the fact that it is not limited in terms of shape, light, or flexibility.

The properties of $\mathrm{ZnO} /$ graphene composite films are different from those of the individual constituent materials. Experimental studies have been conducted on graphene 
composites with $\mathrm{ZnO}$ nanoparticles or nanorods [23-30]. In these studies, the composite films showed superior photovoltaic [31], photocatalytic [32], photoluminescence [33], antibacterial [34], and sensing [35] properties due to the high transmittance, electron collection enhancement, obstruction of electron-hole pair recombination [29], and good contact between the $\mathrm{ZnO}$ and graphene [36]. In general, crystalline $\mathrm{ZnO} /$ graphene composites have been regarded as a promising strategy for enhancing the properties of $\mathrm{ZnO}$ or graphene.

To understand the underlying mechanism of performance change, some scholars have studied crystalline $\mathrm{ZnO}$ /graphene via density functional theory (DFT). The results showed that by changing the layer spacing of $\mathrm{ZnO} /$ graphene, the carrier mobility of the system could be modulated [37], and the O-C bond became stronger, with the bond distance decreased from $1.8 \AA$ [38]. Several studies have investigated the connection mechanism of $\mathrm{ZnO} /$ graphene and its synthesis, exploring the charge transfer between graphene and $\mathrm{ZnO}$ with decreasing distance of the $\mathrm{ZnO} /$ graphene layers and the bond formation of $\mathrm{ZnO} /$ graphene [26], which is due to synergistic interaction in $\mathrm{ZnO} /$ graphene nanocomposites [25].

Most studies have focused on crystalline $\mathrm{ZnO}$ /graphene composite films, but amorphous $\mathrm{ZnO} /$ graphene composite films remain to be explored. Thus, there is the question as to whether an amorphous $\mathrm{ZnO} /$ graphene composite film would retain the high transparency and conductivity of graphene. In this work, through the vacuum thermal evaporation technique, an amorphous $\mathrm{ZnO}$ layer was deposited onto graphene/PET to form an ultrathin flexible composite film.

There are many ways to prepare composite $\mathrm{ZnO} /$ graphene films. The cost of magnetron sputtering technology is high, the efficiency of chemical vapor deposition is low, and wastewater treatment by electrochemical plating is difficult and pollutes the environment. However, the vacuum thermal evaporation method has the advantages of low cost, fast evaporation rate, and environmental friendliness. Therefore, the evaporation method is the best choice [39].

After preparation, we carried out relevant detection techniques and the optical and electrical properties of the amorphous $\mathrm{ZnO} /$ graphene composite film were characterized to clarify the unexpected results, i.e., the significantly lower electrical properties of the composite films compared with those of the graphene sheet. The interfacial chemical effect of amorphous $\mathrm{ZnO}$ /graphene was investigated and analyzed via X-ray photoelectron spectroscopy (XPS) and DFT calculations.

\section{Experimental Method and Theoretical Calculations}

\subsection{Materials}

Graphene/PET composite film was purchased from 2D Carbon Graphene Material Co., Ltd., Changzhou, China (CAS no. of graphene: 1034343-98-0, CAS no. of PET: 25038-59-9). Double-layer graphene was grown via the chemical vapor deposition (CVD) of graphene on a PET substrate with $125 \mu \mathrm{m}$ thickness. The sheet resistance and visible transparency of the graphene/PET were $157 \Omega \cdot \mathrm{sq}^{-1}$ and $90 \%$, respectively. Zinc oxide powder $(\geq 99.99 \%$, 20 mg, CAS no.: 1314-13-2) was purchased from Shanghai Aladdin Biochemical Technology Co., Ltd., Shanghai, China.

\subsection{Device Fabrication}

The fresh graphene/PET flexible substrate was transferred into the vacuum chamber for ultrathin $\mathrm{ZnO}$ layer evaporation at a pressure of $8 \times 10^{-4} \mathrm{~Pa}$ at room temperature. Zinc oxide powder was placed onto a tungsten (W) boat, which was $160 \mathrm{~mm}$ below the substrate. Amorphous $\mathrm{ZnO}$ layers with different thicknesses of 40, 75, and $160 \mathrm{~nm}$ were thermally evaporated under different evaporation voltages (95, 100, and $105 \mathrm{~V}$ ), i.e., the voltage applied on the tungsten boat as a heating source, and the rate of voltage increase was $5 \mathrm{~V} / \mathrm{min}$. A schematic diagram of the parallel resistance of amorphous $\mathrm{ZnO} /$ graphene composite film and the technological parameter graph of the deposition process are shown in Figure 1a,b [40]. The deposition rate of $\mathrm{ZnO}$ film increased nonlinearly 
with the evaporation voltage because the evaporation volume of $\mathrm{ZnO}$ powder depended on the temperature of the tungsten boat, which depended on the evaporation voltage-refer to the inset figure in Figure $1 \mathrm{~b}$.
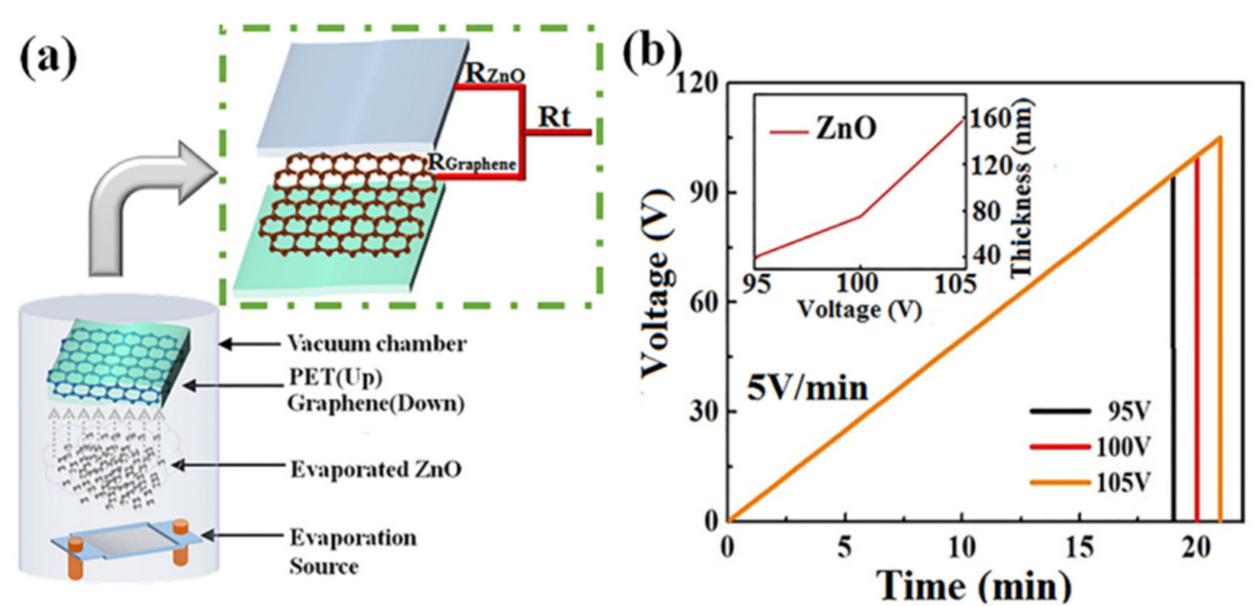

Figure 1. Experimental method and technology: (a) vacuum evaporation plating method and a schematic diagram of the parallel resistance of amorphous $\mathrm{ZnO} /$ graphene/PET film; (b) technological parameter graph of the $\mathrm{ZnO}$ deposition process.

\subsection{Characterization}

\subsubsection{Optoelectronic Characterization}

The samples were cut into $10 \times 10 \mathrm{~mm}^{2}$ samples in a square shape. The electrical properties of the composite films were measured using a HALL 8800 Hall-effect measurement device, which was carried out in four-point mode with gold electrodes by DC voltage in a 4800-gauss magnetic field. The transmittance of composite films was measured using a CARY 5000 UV-VIS-NIR spectrometer in the wavelength region of 175-3300 nm (test coverage: $200-800 \mathrm{~nm}$ ).

\subsubsection{Structure and Morphology Characterization}

The thicknesses of the $\mathrm{ZnO}$ layers were measured using a KLA-Tencor Alpha-Step D-100 profilometer at a speed of $0.03 \mathrm{~mm} / \mathrm{s}$ and stylus force of $0.03 \mathrm{mg}$. The roughness of the substrate was measured by atomic force microscopy (AFM CSPM5500), and the roughness was analyzed using Imager software. The samples were scanned in contact mode using a Tap300Al-G probe under ambient atmosphere. The surface morphologies of the film were obtained using a SIGMA high-definition field-emission scanning electron microscope, which was operated at $15 \mathrm{kV}$. The X-ray diffraction (XRD) patterns of the composite film were recorded using an $\mathrm{X}^{\prime}$ Pert powder X-ray diffractometer with monochromatized $\mathrm{Cu}$ $\mathrm{K} \alpha$ radiation. The tube was operated at a scanning speed of $0.05^{\circ} / \mathrm{s}$ from $20^{\circ}$ to $60^{\circ}$. The structures of graphene and $\mathrm{ZnO} /$ graphene composite film were characterized by transmission electron microscopy (TEM) at $200 \mathrm{kV}$. The TEM samples were prepared by scratching the $\mathrm{ZnO}$ and graphene layers and placing the minimal debris onto amorphous carbon-coated cooper grids. The element distribution and the interfacial chemical bonds were analyzed via a PHI Quantera SXM scanning photoelectron spectrometer, using an $\mathrm{Ar}^{+}$sputtering gun at $1 \mathrm{kV}$ with an etching rate of $3 \mathrm{~nm} / \mathrm{min}$ for standard $\mathrm{SiO}_{2}$.

\subsection{First-Principles Calculations}

The Vienna ab initio simulation package (VASP) code was used to calculate the electron localization function (ELFCAR) of the interfacial models of amorphous $\mathrm{ZnO}$ and graphene. In VASP, the interactions of electrons and ions were described by their projector-augmented wave (PAW) potentials. The generalized gradient approximation parametrized by PerdewBurke-Ernzerhof was used for the electron exchange-correction function. 
In this study, the initial structures of the amorphous $\mathrm{ZnO} /$ graphene interface model were investigated. A cluster model of $(\mathrm{ZnO}) \mathrm{n}$ was selected to represent the amorphous $\mathrm{ZnO}$ model. To better match the $(\mathrm{ZnO}) \mathrm{n}$ clusters and graphene, $\mathrm{n}$ was chosen to be 6 , so that the model had $6 \mathrm{Zn}$ atoms and $6 \mathrm{O}$ atoms. The cluster model of $(\mathrm{ZnO})_{6}$ was obtained after structural optimization. Similar models have been mentioned in other studies [41-43].

The structure of crystalline $\mathrm{ZnO}(2 \times 2 \times 1)$ was obtained from the Materials Project database, with code number 2133; the crystalline $\mathrm{ZnO}$ had a P63mc space group symmetry. The structure of graphene $(2 \times 2)$ was obtained from the Materials Project database, with the code number 990448; the graphene had a P6/mmm space group symmetry. The valence electron configurations were $\mathrm{Zn} 3 \mathrm{~d}^{10} 4 \mathrm{~s}^{2}, \mathrm{O} 2 \mathrm{~s}^{2} \mathrm{p}^{4}$, and C $2 \mathrm{~s}^{2} 2 \mathrm{p}^{2}$.

The two interface models were established. Figure $2 \mathrm{a}$ shows the crystalline $\mathrm{ZnO}$ adjacent to graphene, and Figure $2 b$ shows the amorphous $\mathrm{ZnO}$ adjacent to graphene; for both models, the distance between $\mathrm{O}$ and C was $1.8 \AA$.

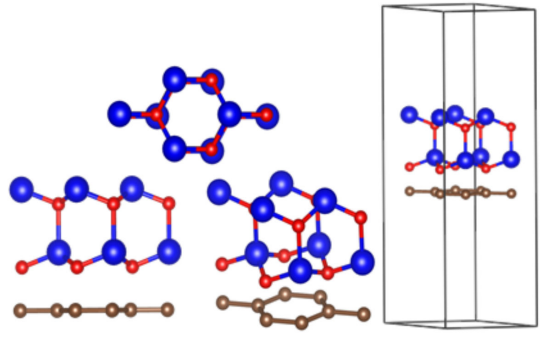

(a) A-Crystal Model

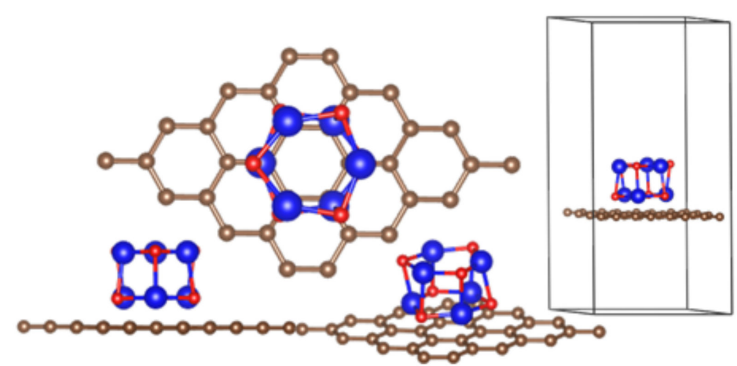

(b) B-Cluster Model

Figure 2. Calculation models: (a) crystal $\mathrm{ZnO} /$ graphene interface model; (b) cluster (amorphous) $\mathrm{ZnO} /$ graphene interface model. Color code: Carbon, brown; Zinc, blue; Oxygen, red.

The cut-off energy in this calculation was $500 \mathrm{eV}$. The convergence threshold for self-consistent-field iteration was set at $10^{-5} \mathrm{eV}$, and the width of the Gaussian smearing was $0.05 \mathrm{eV}$. A Monkhorst-Pack $5 \times 5 \times 5 \mathrm{k}$-point mesh was used for the Brillouin zone integration to compute the electron localization function.

\section{Results and Discussion}

\subsection{Morphology and Phase Structure}

The surface morphological structures of the bare graphene and amorphous $\mathrm{ZnO}$ /graphene composite films are displayed in Figure 3. Figure 3a shows the morphology of graphene/PET, and the inset figure in large scale shows the typical morphological structure of bare graphene. At a lower evaporation voltage of $95 \mathrm{~V}$, the amorphous $\mathrm{ZnO}$ layer with $40 \mathrm{~nm}$ thickness, as measured by the profilometer, showed a loose granular structure (see Figure $3 b$ ). A relatively dense granular structure was observed from the $\mathrm{ZnO}$ layer with $75 \mathrm{~nm}$ thickness, deposited at $100 \mathrm{~V}$ (Figure 3c). Finally, the ZnO layer with $160 \mathrm{~nm}$ thickness at the highest voltage of $105 \mathrm{~V}$ showed a continuous, dense structure with some agglomerates (Figure 3d). The particle sizes, composed of many small particles of the amorphous $\mathrm{ZnO}$ films decreased with increasing thickness or evaporation voltage. In other words, the particles were unlikely to cluster as the evaporation voltage increased.

It is worth mentioning that the range of $\mathrm{ZnO}$ particle sizes of the film with $40 \mathrm{~nm}$ thickness was from $10 \mathrm{~nm}$ to over $50 \mathrm{~nm}$. The roughnesses of the graphene and the films with thickness of 40,75, and $160 \mathrm{~nm}$ were 5, 46, 49, and $77 \mathrm{~nm}$, respectively. This proved that the $\mathrm{ZnO}$ film with $40 \mathrm{~nm}$ thickness was un-continuous. The $\mathrm{ZnO}$ films with thicknesses of $75 \mathrm{~nm}$ and $160 \mathrm{~nm}$ were dense and continuous.

The phase structures of the bare graphene and $\mathrm{ZnO} /$ graphene composite film were characterized by XRD, and the results are shown in Figure 4a. Moreover, the TEM morphological images are displayed in Figure $4 \mathrm{~b}, \mathrm{~d}$. The diffraction patterns from selected-area electron diffraction (SAED) of the bare graphene and amorphous $\mathrm{ZnO} /$ graphene composite film are given in Figure 4c,e, which correspond to Figure $4 b, d$, respectively. 

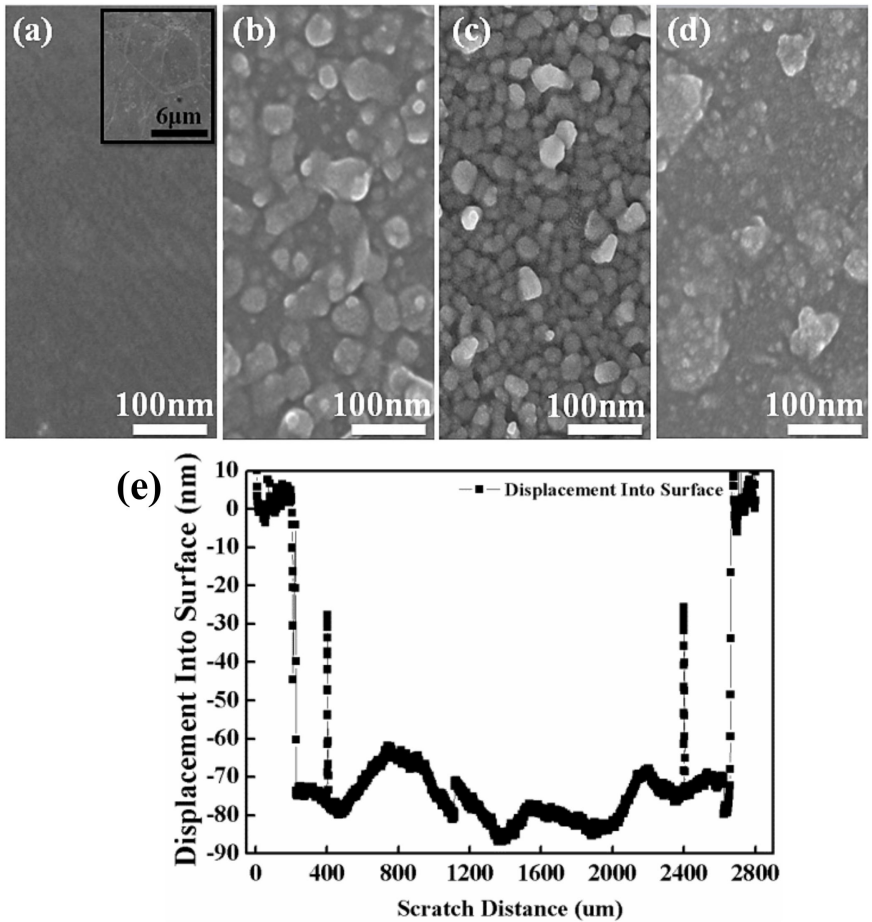

Figure 3. Top-view FESEM images: (a) bare graphene/PET and different $\mathrm{ZnO}$ films with thickness of (b) $40 \mathrm{~nm}$, (c) $75 \mathrm{~nm}$, and (d) $160 \mathrm{~nm}$ which were evaporated onto a graphene/PET substrate at different voltages of 95, 100, and $105 \mathrm{~V}$; (e) profilometer scan of $\mathrm{ZnO}$ film with $75 \mathrm{~nm}$ thickness.
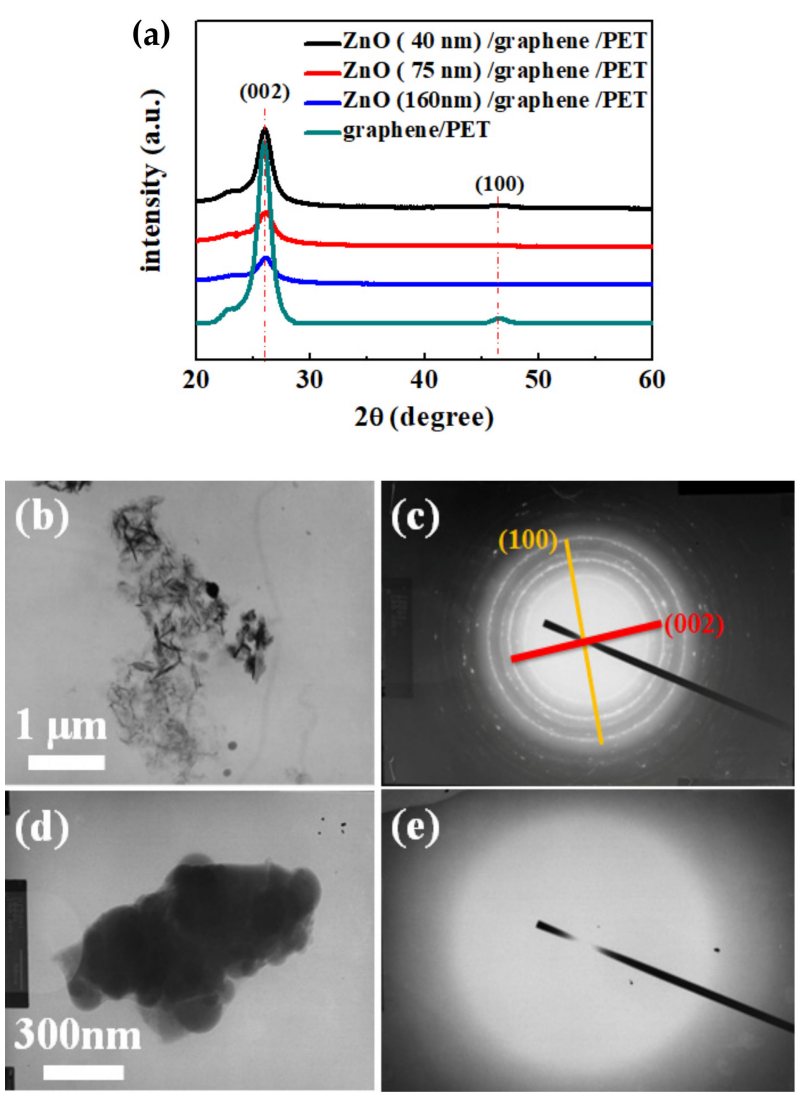

Figure 4. (a) X-ray diffraction spectra of graphene/PET and $\mathrm{ZnO}(40,75$, and $160 \mathrm{~nm}$ thickness)/graphene/PET; $(\mathbf{b}, \mathbf{c})$ TEM image and SAED pattern of graphene/PET; $(\mathbf{d}, \mathbf{e})$ TEM image and SAED pattern of $\mathrm{ZnO} /$ graphene/PET. 
From the X-ray diffractometer (XRD) patterns (Figure 4a), the intensity of the bare graphene peak (002) at $26.29^{\circ}$ was significant [44]. With the increase in the $\mathrm{ZnO}$ layer thickness, the graphene peak intensity decreased. Moreover, the SAED pattern of the TEM result shows the graphene oxide peak (100) at $46.48^{\circ}$ (Figure 4c). The graphene oxide peak (100) at $46.48^{\circ}$ may be due to weak oxidation of the graphene sample [45]. The SAED pattern showed (002) and (100) polycrystal diffraction circles, which are due to the graphene flakes' random arrays of graphene debris, caused by the scratching during the TEM sample preparation.

In addition, there is no (002) diffraction peak at $34.40^{\circ}$ in Figure $4 \mathrm{a}$ and no diffraction circle or patterns of $\mathrm{ZnO}$ (002) in Figure 4e; hence, the structure of the $\mathrm{ZnO}$ layers deposited on the graphene/PET via thermal evaporation was amorphous.

\subsection{Optical and Electrical Properties}

The transparent spectra of the graphene/PET and amorphous $\mathrm{ZnO} /$ graphene/PET are displayed in Figure 5. The average transparency of the $\mathrm{ZnO} /$ graphene/PET composite film was $90 \%$ at the $600 \mathrm{~nm}$ wavelength range. The slightly lower transparency of the composite film with a $75 \mathrm{~nm} \mathrm{ZnO} \mathrm{layer} \mathrm{within} \mathrm{the} \mathrm{300-600} \mathrm{nm} \mathrm{wavelength} \mathrm{might} \mathrm{be} \mathrm{due}$ to the granular structure (Figure 3c), which resulted in light scattering and absorption functions of the film [46].

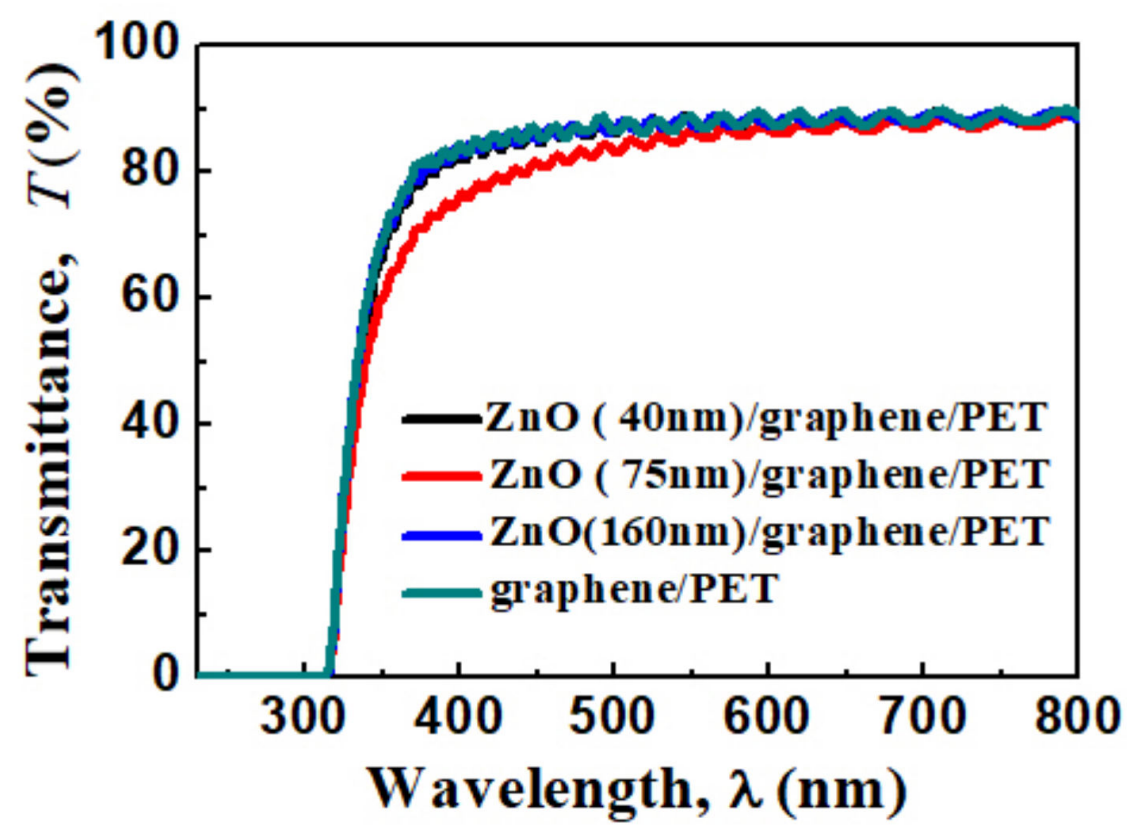

Figure 5. Optical transmittance spectra of graphene/PET and ZnO (40, 75, and $160 \mathrm{~nm}$ thickness)/graphene/PET.

Table 1 presents the electrical properties of the graphene/PET, amorphous $\mathrm{ZnO}$ / graphene composite film, and pure $\mathrm{ZnO}$. $\mathrm{ZnO}$ is likely in the form of molecules or clusters because there is no assistance of an electron or ion beam during the deposition procedure and no ionization process. Therefore, the deficit of oxygen in the $\mathrm{ZnO}$ films should be limited, and oxygen vacancies, which would contribute an improvement in electrical properties, are limited. That is the reason why the sheet resistance of the pure $\mathrm{ZnO}$ film is as high as $10^{5} \Omega \cdot \mathrm{sq}^{-1}$, while the carrier concentration and mobility are as low as $10^{17} \mathrm{~cm}^{-3}$ and $6-10 \mathrm{~cm}^{2} \cdot \mathrm{v}^{-1} \cdot \mathrm{s}^{-1}$, respectively. 
Table 1. Electrical properties of the amorphous $\mathrm{ZnO} /$ graphene composite film.

\begin{tabular}{cccccc}
\hline Thickness of ZnO Layers, $\mathbf{n m}$ & $\mathbf{0}$ & $\mathbf{4 0}$ & $\mathbf{7 5}$ & $\mathbf{1 6 0}$ & Pure ZnO \\
\hline Sheet resistance, $\times 10^{2} \Omega \cdot \mathrm{sq}^{-1}$ & 1.57 & 55.30 & 12.70 & 9.06 & 1000 \\
Carrier concentration, $\times 10^{18} \mathrm{~cm}^{-3}$ & 964.00 & 0.13 & 1.36 & 0.47 & 0.10 \\
Carrier mobility, $\times 10^{2} \mathrm{~cm}^{2} \cdot \mathrm{v}^{-1} \cdot \mathrm{s}^{-1}$ & 6.06 & 20.40 & 4.81 & 9.09 & $0.06-0.10$ \\
\hline
\end{tabular}

The continuous and dense $\mathrm{ZnO}$ layer makes relatively little contribution to the sheet resistance of the composite film. The parallel resistance of the graphene and $\mathrm{ZnO}$ layers was equivalent to that of a single resistor; that is, $1 / R_{t}=1 / R_{Z n O}+1 / R_{\text {graphene }}$ [47]. According to the above principle, the predicted composite film sheet resistances should be only slightly less than that of bare graphene. At the same time, some scholars found that the conductivity of crystal $\mathrm{ZnO} / \mathrm{Graphene} \mathrm{composite} \mathrm{film} \mathrm{increased} \mathrm{significantly} \mathrm{[48].} \mathrm{How-}$ ever, the composite films' sheet resistances were almost an order of magnitude greater than the levels for bare graphene. The bulk free charge carrier concentrations of the composite films $\left(10^{17-18} \mathrm{~cm}^{-3}\right)$ were remarkably lower than that of bare graphene $\left(10^{20} \mathrm{~cm}^{-3}\right)$. To determine the mechanism of the loss of free charge carriers in the $\mathrm{ZnO} /$ graphene composite film, we focused on the interfacial chemical effect of amorphous $\mathrm{ZnO} /$ graphene.

\subsection{The Chemical Bonds at the Amorphous $\mathrm{ZnO} /$ Graphene Interface}

The above mentioned amorphous $\mathrm{ZnO} /$ graphene/PET films exhibited unexpectedly deteriorative electrical properties. The amorphous $\mathrm{ZnO} /$ graphene/PET sample with $\mathrm{ZnO}$ thickness of $75 \mathrm{~nm}$ was selected for XPS analysis, which provided the elemental composition and bonding information.

The distributions of $\mathrm{C}, \mathrm{O}$, and $\mathrm{Zn}$ elements at different depths of the $\mathrm{ZnO}$ /graphene/ PET composite film are shown in Figure 6. The proportions of $\mathrm{C}, \mathrm{Zn}$, and $\mathrm{O}$ remained stable up to a depth of about $90 \mathrm{~nm}$. The different thicknesses of the $\mathrm{ZnO}$ layer were due to errors in the two measurement techniques. With further sputtering on the composite film up to a depth of $140 \mathrm{~nm}$, only $C$ from the graphene remained. XPS studies on graphene revealed that $1 \mathrm{kV} \mathrm{Ar}{ }^{+}$ion bombardment did not damage the graphene hexahedral structure [49-51]; therefore, with the increase in sputtering time, presented as "depth" in Figure 6, O and Zn from $\mathrm{ZnO}$ were sputtered away and $\mathrm{C}$ from graphene remained. The information of $\mathrm{O}$ and $\mathrm{Zn}$ at the amorphous $\mathrm{ZnO}$ /graphene interface became weak, and that of $\mathrm{C}$ was stronger. Thus, it can be concluded that the graphene remained between the amorphous $\mathrm{ZnO}$ layer and PET substrate, which was not affected by the evaporation procedure. In other word, the graphene should contribute its conductivity to the composite films.

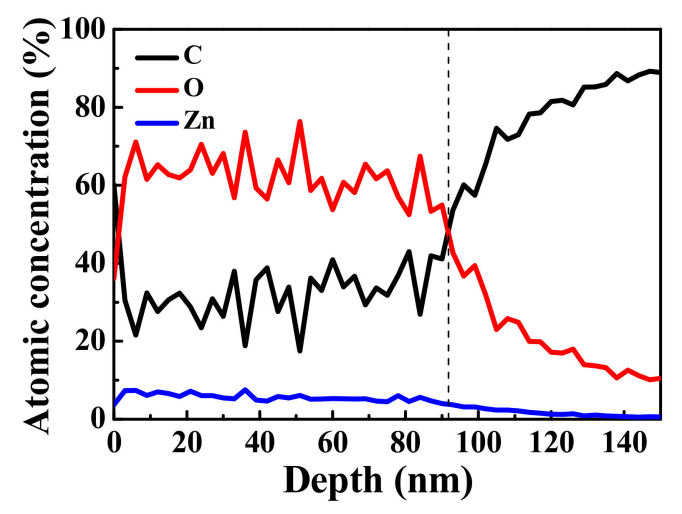

Figure 6. XPS spectra of $\mathrm{C}, \mathrm{O}$, and $\mathrm{Zn}$ distributions vs. depth (sputtering time) of $\mathrm{ZnO} /$ graphene/ PET film.

The XPS C1s and O1s spectra were fitted by the Gaussian-Lorenzian (GL30) functions to reveal the chemical bonding state of the carbon and oxygen (Figure 7a-f). Casa XPS software was applied in this analysis. The analysis result of the graphene surface 
(Figure 7a) showed the presence of $\mathrm{C}-\mathrm{C}, \mathrm{C}-\mathrm{OH}, \mathrm{C}-\mathrm{O}-\mathrm{C}, \mathrm{C}=\mathrm{O}$, and $\mathrm{O}-\mathrm{C}=\mathrm{O}$, resulting from air and graphene [46]. Moreover, $\mathrm{C}-\mathrm{C}, \mathrm{C}-\mathrm{OH}$, and $\mathrm{C}-\mathrm{O}-\mathrm{C}$ occurred at the graphene/PET interface (Figure $7 \mathrm{~b}$ ); in the interface, $\mathrm{C}=\mathrm{O}$ bonds were absent, and $\mathrm{O}-\mathrm{C}=\mathrm{O}$ and $\mathrm{C}-\mathrm{O}$ $\mathrm{C}$ bonds became very weak, which means that only graphene and a small quantity of graphene oxide existed [46]. Figure $7 \mathrm{c}$ shows the chemical bonds at the interface of amorphous $\mathrm{ZnO} /$ graphene/PET, where $\mathrm{C}-\mathrm{C}, \mathrm{C}-\mathrm{OH}, \mathrm{C}-\mathrm{O}-\mathrm{C}$, and $\mathrm{C}=\mathrm{O}$ bonds existed. The intensity and the integrated area of the $\mathrm{C}-\mathrm{O}-\mathrm{C}$ and $\mathrm{C}=\mathrm{O}$ peaks at the interface of amorphous $\mathrm{ZnO} /$ graphene were much higher and larger than those of the peaks at the graphene/PET interface. The much higher and larger $\mathrm{C}=\mathrm{O}$ and $\mathrm{C}-\mathrm{O}-\mathrm{C}$ peaks at the interface of amorphous $\mathrm{ZnO}$ /graphene suggests that the $\mathrm{C}$ from graphene combined with the $\mathrm{O}$ from $\mathrm{ZnO}$; therefore, the free $\pi$ electrons of the graphene were bonded, and the conductivity of the composite films dropped dramatically.
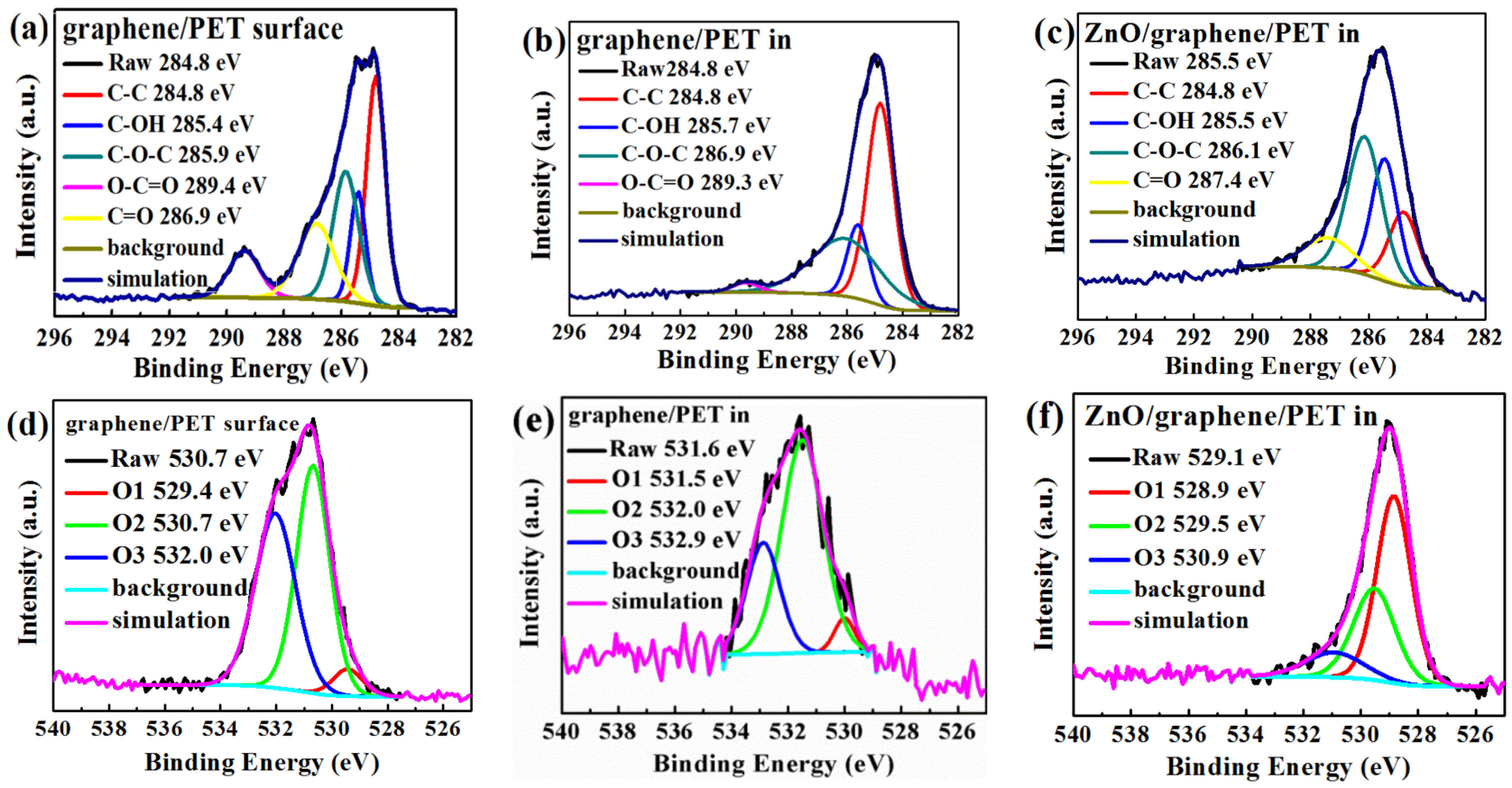

Figure 7. The C1s XPS spectra of the (a) graphene surface, (b) graphene/PET interface, and (c) ZnO/graphene interface; the O1s XPS spectra of the (d) graphene surface, (e) graphene/PET interface, and (f) ZnO/graphene interface.

The binding energies of $\mathrm{O} 1$ at $530.0-531.6 \mathrm{eV}$ overlapped and were identified as $\mathrm{C}=\mathrm{O}$ and $\mathrm{C}-\mathrm{O}$ bonds; the binding energies of $\mathrm{O} 2$ and $\mathrm{O} 3$ at $532.4-533.3 \mathrm{eV}$ were identified as $\mathrm{C}-\mathrm{OH}$ [49]. The two O1s positions in the XPS spectra of the graphene surface (Figure 7d) and the graphene/PET interface (Figure 7e) were similar, but the $\mathrm{O} 1$ peak at the interface of the amorphous $\mathrm{ZnO} /$ graphene/PET (Figure 7f) sharply erupted. This indicates that $\mathrm{C}=\mathrm{O}$ and $\mathrm{C}-\mathrm{O}$ bonds were formed at the interface of the amorphous $\mathrm{ZnO} /$ graphene again. This evidence further proves that $\mathrm{C}$ from graphene combined with $\mathrm{O}$ from the amorphous $\mathrm{ZnO}$ layer.

One may argue that the oxygens of $\mathrm{C}=\mathrm{O}$ and $\mathrm{C}-\mathrm{O}$ came from pollution of the graphene surface because the graphene was used as received, without surface cleaning by the sputtering process. Although it is possible that the oxygen came from surface pollution, the possibility is low, due to the following reasons: First, the graphene was kept in a vacuum bag before use. Second, the fresh graphene was placed in a vacuum chamber, the pressure of which was as low as $10^{-4} \mathrm{~Pa}$; that is, the oxygen not bonded with the $\mathrm{C}$ of the graphene was pumped away. Third, the oxygen atoms in the chamber were only provided by $\mathrm{ZnO}$ molecules.

When the $\mathrm{ZnO}$ powder was evaporated by the vacuum thermal technique, there were $\mathrm{ZnO}$ molecules or clusters between the hot tungsten boat and cold graphene/PET substrate. 
There was not enough energy for $\mathrm{ZnO}$ molecules to crystalize, and therefore, the films remained amorphous. The oxide $(\mathrm{O})$ in $\mathrm{ZnO}$ molecules was attracted by the carbon $(\mathrm{C})$ in graphene according to the first-principles calculations, which resulted in the formation of $\mathrm{C}=\mathrm{O}$ and $\mathrm{C}-\mathrm{O}-\mathrm{C}$ bonds.

In general, the formation of $\mathrm{C}=\mathrm{O}$ and $\mathrm{C}-\mathrm{O}-\mathrm{C}$ bonds at the interface of amorphous $\mathrm{ZnO} /$ graphene caused the bonding of the $\pi$ electrons of the graphene and thereby limited their mobility. In other words, the formation of $\mathrm{C}=\mathrm{O}$ and $\mathrm{C}-\mathrm{O}-\mathrm{C}$ bonds should be responsible for the decrease in the bulk free charge carriers in the amorphous $\mathrm{ZnO} /$ graphene composite film, which is contradictory to earlier studies on crystalline $\mathrm{ZnO} /$ graphene composites. Therefore, we believe that the amorphous structure of the $\mathrm{ZnO}$ layer is the cause of the formation of the $\mathrm{C}=\mathrm{O}$ and $\mathrm{C}-\mathrm{O}-\mathrm{C}$ chemical bonds.

\subsection{Electron Localization Functions}

The electron localization functions (ELFs) were calculated to further investigate the bonding natures at the crystal (Figure 8a) and amorphous (Figure 8b) $\mathrm{ZnO} /$ graphene interfaces. It can be seen from Figure $8 \mathrm{a}, \mathrm{b}$ that the electron clouds are localized around $\mathrm{O}$ atoms (yellow color) and delocalized from $\mathrm{Zn}$ atoms, whether in the crystal $\mathrm{ZnO}$ model $\mathrm{A}$ or the amorphous $\mathrm{ZnO}$ model $\mathrm{B}$, which indicates the ionic bonds of $\mathrm{ZnO}$. Also, the covalent $\mathrm{C}-\mathrm{C}$ bond in graphene can be found in Figure 8, in which the electron localization density of graphene is shown to be fair. The clear distinctions between the two models are as follows: The localized electron clouds $\mathrm{C}$ and $\mathrm{O}$ are separated between crystal $\mathrm{ZnO}$ and graphene, and there is no bond formed between the $\mathrm{O}$ of crystalline $\mathrm{ZnO}$ and the $\mathrm{C}$ of graphene (Figure $8 \mathrm{a}, \mathrm{c}$ ). The localized electron cloud of $\mathrm{O}$ from amorphous $\mathrm{ZnO}$ joins together with that of $C$ from graphene, which indicates the formation of covalent bonds between the $\mathrm{O}$ of amorphous $\mathrm{ZnO}$ and the $\mathrm{C}$ of graphene (Figure $8 \mathrm{~b}$,d). In other words, the crystalline $\mathrm{ZnO}$ and graphene do not form chemical bonds, while $\mathrm{C}-\mathrm{O}$ covalent bonds are formed between the amorphous $\mathrm{ZnO}$ and graphene.
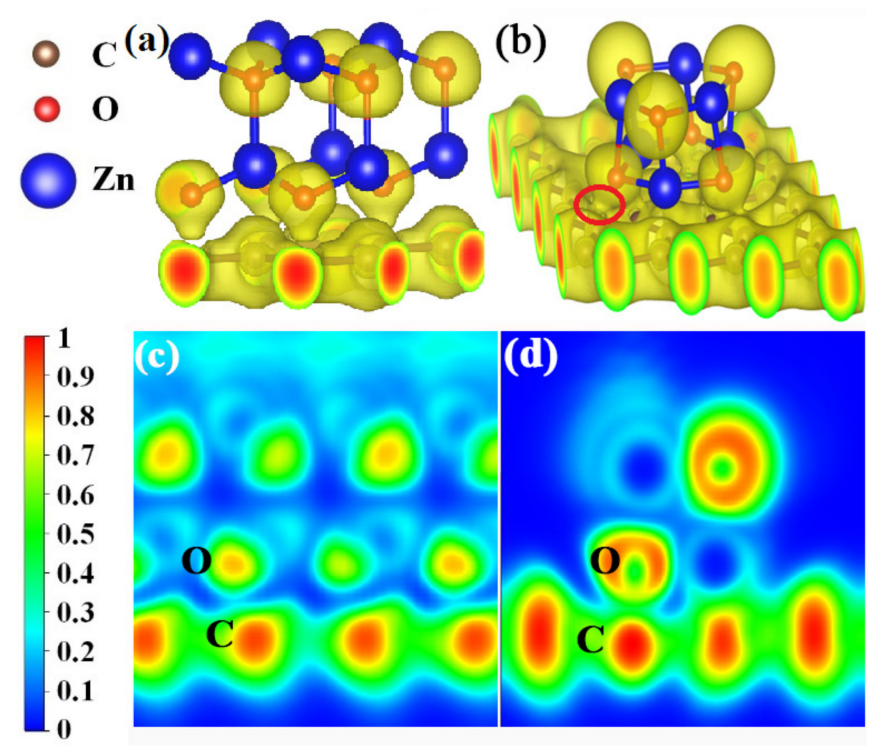

Figure 8. $(\mathbf{a}, \mathbf{b})$ Three-dimensional local electron density distributions with isosurface plots of the $\mathrm{ZnO} /$ graphene interface; yellow regions indicate accumulation of electrons. The isosurface plots (with a value of $0.45 \mathrm{eV} / \mathrm{bohr}^{3}$ ) clearly illustrate the electron distribution localized around $\mathrm{O}$ atoms. (c,d) The two-dimensional electron localization function for the $\mathrm{ZnO} /$ graphene interface. Blue regions are domains of low electron localization, while red regions are domains of high electron localization. ELF values of 0 and 1 correspond to perfect delocalization and localization, respectively. 


\section{Conclusions}

In this study, amorphous $\mathrm{ZnO}$ layers on flexible graphene/PET substrates were prepared via vacuum thermal evaporation at room temperature. With the increase in the amorphous $\mathrm{ZnO}$ layer thickness, the morphological structure of the layer changed from loose un-continuous granular, to relatively dense granular, to continuous and dense. The transparency of the composite films within the visible spectrum was comparable to that of graphene/PET. Its electrical properties were better than those of the pure $\mathrm{ZnO}$ but less than those of graphene. For example, the bulk free charge carrier concentrations of the composite films $\left(0.13,1.36\right.$, and $0.47 \times 10^{18} \mathrm{~cm}^{-3}$ corresponding to composite films with thickness of 40,75 , and $160 \mathrm{~nm}$ ) were remarkably lower than that of bare graphene $\left(964 \times 10^{18} \mathrm{~cm}^{-3}\right)$ and better than that of $\mathrm{ZnO}\left(0.10 \times 10^{18} \mathrm{~cm}^{-3}\right)$. The results from XPS analysis showed the formation of $\mathrm{C}=\mathrm{O}$ and $\mathrm{C}-\mathrm{O}-\mathrm{C}$ bonds between $\mathrm{O}$ from $\mathrm{ZnO}$ and $\mathrm{C}$ from graphene at the interface of $\mathrm{ZnO}$ and graphene. The first-principles calculations revealed that the oxide from amorphous $\mathrm{ZnO}$ tended to be attracted by $\mathrm{C}$ from graphene to form strong, dense localized electron clouds. The electrical properties of the composite films deteriorated because of the formation of the $\mathrm{C}=\mathrm{O}$ and $\mathrm{C}-\mathrm{O}-\mathrm{C}$ chemical bonds at the interface of amorphous $\mathrm{ZnO} /$ graphene, which restrained the transfer of the $\pi$ electrons from graphene. This discovery is still helpful for the development of transparent conductive films.

Author Contributions: Conceptualization, Y.Z.; methodology, Z.Z., F.F., and X.T.; software, Z.Z.; validation, Z.Z., F.F., and Y.Z.; formal analysis, Z.Z., F.F., and J.W. (Junsheng Wu); investigation, Z.Z. and F.F.; resources, Z.Z., F.F., and X.T.; data curation, Z.Z., F.F., and J.W. (Junsheng Wu); writingoriginal draft preparation, Z.Z., Z.L., and D.S.; writing-review and editing, Z.Z., Y.Z., Z.L., and D.S.; visualization, Z.Z.; supervision, Z.L. and J.W. (Jian Wang); project administration, Z.Z.; funding acquisition, Y.Z. All authors have read and agreed to the published version of the manuscript.

Funding: This research was funded by National Natural Science Foundation of China (No. 51672119 and 51972155) and the project of Young Teachers in the Higher Education Institutions of USTL (No. 2017QN13).

Institutional Review Board Statement: Not applicable.

Informed Consent Statement: Not applicable.

Data Availability Statement: The data presented in this study are available on request from the corresponding author.

Conflicts of Interest: On behalf of all authors, the corresponding author states that there are no conflicts of interest.

\section{References}

1. Zhang, Q.; Dandeneau, C.S.; Zhou, X.; Cao, G. ZnO Nanostructures for Dye-Sensitized Solar Cells. Adv. Mater. 2009, 21, 4087-4108. [CrossRef]

2. Onwona-Agyeman, B.; Nakao, M.; Kohno, T.; Liyanage, D.; Murakami, K.; Kitaoka, T. Preparation and characterization of sputtered aluminum and gallium co-doped $\mathrm{ZnO}$ films as conductive substrates in dye-sensitized solar cells. Chem. Eng. J. 2013, 219, 273-277. [CrossRef]

3. Chang, J.F.; Kuo, H.H.; Leu, I.C.; Hon, M.H. The effects of thickness and operation temperature on ZnO:Al thin film CO gas sensor. Sens. Actuators B Chem. 2002, 84, 258-264. [CrossRef]

4. Wan, Q.; Li, Q.H.; Chen, Y.J.; Wang, T.H.; He, X.L.; Li, J.P.; Lin, C.L. Fabrication and ethanol sensing characteristics of ZnO nanowire gas sensors. Appl. Phys. Lett. 2004, 84, 3654-3656. [CrossRef]

5. Zhu, L.; Zeng, W. Room-temperature gas sensing of ZnO-based gas sensor: A review. Sens. Actuators A Phys. 2017, 267, $242-261$. [CrossRef]

6. Nakanishi, Y.; Miyake, A.; Kominami, H.; Aoki, T.; Hatanaka, Y.; Shimaoka, G. Preparation of ZnO thin films for high-resolution field emission display by electron beam evaporation. Appl. Surf. Sci. 1999, 142, 233-236. [CrossRef]

7. Ma, Y.K.; Yao, N.; Gao, Z.F.; Wang, A.H.; Zhang, B.L. The Preparation of ZnO Film by Two Step Chemical Deposition Method and Its Field Emission Properties. Chin. J. Lumin. 2009, 30, 368-372.

8. Zulkifli, Z.; Subramanian, M.; Tsuchiya, T.; Rosmi, M.S.; Ghosh, P.; Kalita, G.; Tanemura, M. Highly transparent and conducting $\mathrm{C}: \mathrm{ZnO}$ thin film for field emission displays. RSC Adv. 2014, 4, 64763-64770. [CrossRef] 
9. Coleman, V.A.; Jagadish, C. Chapter 1-Basic Properties and Applications of ZnO. In Zinc Oxide Bulk, Thin Films and Nanostructures: Processing, Properties, and Applications; Jagadish, C., Pearton, S., Eds.; Elsevier: Amsterdam, The Netherlands, 2006 ; pp. 1-20.

10. Sivaramakrishnan, K. Zinc Oxide Transparent Thin Films For Optoelectronics. Ph.D. Thesis, Arizona State University, Tempe, AZ, USA, 2010.

11. Litton, C.W.; Reynolds, D.C.; Collins, T.C. Zinc Oxide Materials for Electronic and Optoelectronic Device Applications; Wiley: Hoboken, NJ, USA, 2011; p. 386.

12. Zhang, L.; Xing, Y.; He, N.; Zhang, Y.; Lu, Z.; Zhang, J.; Zhang, Z. Preparation of Graphene Quantum Dots for Bioimaging Application. J. Nanosci. Nanotechnol. 2012, 12, 2924-2928. [CrossRef]

13. Galiotis, C.; Frank, O.; Koukaras, E.N.; Sfyris, D. Graphene Mechanics: Current Status and Perspectives. Annu. Rev. Chem. Biomol. Eng. 2015, 6, 121-140. [CrossRef]

14. Akinwande, D.; Brennan, C.J.; Bunch, J.S.; Egberts, P.; Felts, J.R.; Gao, H.; Huang, R.; Kim, J.S.; Li, T.; Li, Y. A Review on Mechanics and Mechanical Properties of 2D Materials-Graphene and Beyond. Extrem. Mech. Lett. 2017, 13, 42-77. [CrossRef]

15. Falkovsky, L.A. Optical properties of graphene and IV-VI semiconductors. Phys. Uspekhi 2008, 51, 923-934. [CrossRef]

16. Deng, H.Y. Optical properties of graphene. J. Exp. Theor. Phys. 2015, 115, 496-508.

17. Wang, F.; Shi, S. 3-Optical properties of graphene. In 2D Materials; Avouris, P., Heinz, T.F., Low, T., Eds.; Cambridge University Press: Cambridge, UK, 2017; pp. 38-51.

18. Bunch, J.S. Mechanical and Electrical Properties of Graphene Sheets. Ph.D. Thesis, Cornell University, Ithaca, NY, USA, 2008.

19. Hussain, S.; Iqbal, M.; Park, J.; Ahmad, M.; Singh, J.; Eom, J.; Jung, J. Physical and electrical properties of graphene grown under different hydrogen flow in low pressure chemical vapor deposition. Nanoscale Res. Lett. 2014, 9, 546. [CrossRef] [PubMed]

20. Han, T.-H.; Lee, Y.; Choi, M.-R.; Woo, S.-H.; Bae, S.-H.; Hong, B.; Ahn, J.-H.; Lee, T.W. Extremely efficient flexible organic light-emitting diodes with modified graphene anode. Nat. Photon. 2012, 6, 105-110. [CrossRef]

21. Panth, M.; Cook, B.; Alamri, M.; Ewing, D.; Wilson, A.; Wu, J.Z. Flexible Zinc Oxide Nanowire Array/Graphene Nanohybrid for High-Sensitivity Strain Detection. ACS Omega 2020, 5, 27359-27367. [CrossRef]

22. Atanacio-Sánchez, X.; Pech-Rodríguez, W.J.; Armendáriz-Mireles, E.N.; Castillo-Robles, J.A.; Meléndez-González, P.C.; RochaRangel, E. Improving performance of ZnO flexible dye sensitized solar cell by incorporation of graphene oxide. Microsyst. Technol. 2020, 26, 3591-3599. [CrossRef]

23. Li, B.; Liu, T.; Wang, Y.; Wang, Z. ZnO/graphene-oxide nanocomposite with remarkably enhanced visible-light-driven photocatalytic performance. J. Colloid Interface Sci. 2012, 377, 114-121. [CrossRef] [PubMed]

24. Zhou, X.; Shi, T.; Zhou, H. Hydrothermal preparation of ZnO-reduced graphene oxide hybrid with high performance in photocatalytic degradation. Appl. Surf. Sci. 2012, 258, 6204-6211. [CrossRef]

25. Lee, H.S.; Man, M.T.; Park, K.-D.; Oh, H.M.; Kim, J.; Jeong, H.; Kim, Y.H.; Jeong, M.S. Heterogeneous nucleation and high orientation of $\mathrm{ZnO}$ nanorods on graphene. J. Korean Phys. Soc. 2015, 67, 1819-1823. [CrossRef]

26. Parameshwari, R.; Jothivenkatachalam, K.; Banks, C.E.; Jeganathan, K. Acid-free co-operative self-assembly of graphene-ZnO nanocomposites and its defect mediated visible light photocatalytic activities. Phys. B Condens. Matter 2017, 506, 32-41. [CrossRef]

27. Boukhoubza, I.; Khenfouch, M.; Achehboune, M.; Mothudi, B.M.; Zorkani, I.; Jorio, A. Graphene oxide/ZnO nanorods/graphene oxide sandwich structure: The origins and mechanisms of photoluminescence. J. Alloys Compd. 2019, 797, 1320-1326. [CrossRef]

28. Haghshenas, S.S.P.; Nemati, A.; Simchi, R.; Kim, C.-U. Photocatalytic and photoluminescence properties of ZnO/graphene quasi core-shell nanoparticles. Ceram. Int. 2019, 45, 8945-8961. [CrossRef]

29. Raizada, P.; Sudhaik, A.; Singh, P. Photocatalytic water decontamination using graphene and ZnO coupled photocatalysts: A review. Mater. Sci. Energy Technol. 2019, 2, 509-525. [CrossRef]

30. Wang, L.; Li, Z.; Chen, J.; Huang, Y.; Zhang, H.; Qiu, H. Enhanced photocatalytic degradation of methyl orange by porous graphene/ZnO nanocomposite. Environ. Pollut. 2019, 249, 801-811. [CrossRef] [PubMed]

31. Yan, Y.; Yang, H.; Yi, Z.; Xian, T. NaBH4-Reduction Induced Evolution of Bi Nanoparticles from BiOCl Nanoplates and Construction of Promising Bi@BiOCl Hybrid Photocatalysts. Catalysts 2019, 9, 795. [CrossRef]

32. Pogacean, F.; Ştefan, M.; Toloman, D.; Popa, A.; Leostean, C.; Turza, A.; Coros, M.; Pana, O.; Pruneanu, S. Photocatalytic and Electrocatalytic Properties of NGr-ZnO Hybrid Materials. Nanomaterials 2020, 10, 1473. [CrossRef]

33. Hwang, S.; Shin, D.; Kim, C.O.; Hong, S.; Kim, M.; Kim, J.; Lim, K.; Kim, S.; Choi, S.-H.; Ahn, K.; et al. Comment on "PlasmonEnhanced Ultraviolet Photoluminescence from Hybrid Structures of Graphene/ZnO Films" Reply. Phys. Rev. Lett. 2010, 105, 127403. [CrossRef] [PubMed]

34. Sanmugam, A.; Vikraman, D.; Park, H.J.; Kim, H.-S. One-Pot Facile Methodology to Synthesize Chitosan-ZnO-Graphene Oxide Hybrid Composites for Better Dye Adsorption and Antibacterial Activity. Nanomaterials 2017, 7, 363. [CrossRef]

35. Xia, Y.; Li, R.; Chen, R.; Wang, J.; Xiang, L. 3D Architectured Graphene/Metal Oxide Hybrids for Gas Sensors: A Review. Sensors 2018, 18, 1456. [CrossRef]

36. Yin, Z.; Wu, S.; Zhou, X.; Huang, X.; Zhang, Q.; Boey, F.; Zhang, H. Electrochemical deposition of ZnO nanorods on transparent reduced graphene oxide electrodes for hybrid solar cells. Small 2010, 6, 307-312.

37. Guo, X.; Zhou, Y.G. Band gaps of graphene on layered ZnO substrate: A first principles study. J. Appl. Phys. 2013, 113, 054307. [CrossRef]

38. Liu, Z.; Ge, D.; Yang, P. Structure and interfacial properties investigation for ZnO/graphene interface. Mater. Chem. Phys. 2019, 229, 1-5. [CrossRef] 
39. Olayinka, A.; Akinlabi, E.; Oladijo, P.; Akinlabi, S.; Ude, A. Overview of thin film deposition techniques. Aims Mater. Sci. 2019, 6, 174-199.

40. Tong, X.; Zhao, Z.; Wu, J.; Zhou, Y.; Kelly, P.; Gao, P. Growth of GaN by vacuum thermal evaporation on flexible graphene/PET substrates. Nanosci. Nanotechnol. Lett. 2018, 10, 329-336. [CrossRef]

41. Kapila, N.; Jindal, V.K.; Sharma, H. The role of $\mathrm{N}$ dopant in inducing ferromagnetism in $(\mathrm{ZnO})_{n}$ clusters $(n=1-16)$. J. Phys. Condens. Matter 2011, 23, 446006. [CrossRef] [PubMed]

42. Sharma, H.; Singh, R. Spin-polarized density functional investigation into ferromagnetism in C-doped $(\mathrm{ZnO})_{n}$ clusters; $n=1-12$, 16. J. Phys. Condens. Matter 2011, 23, 106004. [CrossRef] [PubMed]

43. Demiroglu, I.; Woodley, S.M.; Sokol, A.A.; Bromley, S.T. From monomer to monolayer: A global optimisation study of (ZnO)n nanoclusters on the Ag surface. Nanoscale 2014, 6, 14754-14765. [CrossRef] [PubMed]

44. Stobinski, L.; Lesiak, B.; Malolepszy, A.; Mazurkiewicz, M.; Mierzwa, B.; Zemek, J.; Jiricek, P.; Bieloshapka, I. Graphene oxide and reduced graphene oxide studied by the XRD, TEM and electron spectroscopy methods. J. Electron. Spectrosc. Relat. Phenom. 2014, 195, 145-154. [CrossRef]

45. Zhu, Y.; Murali, S.; Stoller, M.D.; Ganesh, K.J.; Cai, W.; Ferreira, P.J.; Pirkle, A.; Wallace, R.M.; Cychosz, K.A.; Thommes, M. Carbon-based supercapacitors produced by activation of graphene. Science 2011, 332, 1537.

46. Amra, C.; Grèzes-Besset, C.; Bruel, L. Comparison of surface and bulk scattering in optical multilayers. Appl. Opt. 1993, 32, 5492-5503. [CrossRef]

47. Liu, S.N.; Zhou, Y.W.; Sha, T.Y.; Wu, F.Y. Fabrication and Characterization of the AZO/Ag/AZO Transparent Conductive Films Prepared by RF Magnetron Sputtering Using Powder Targets. Nanosci. Nanotechnol. Lett. 2015, 7, 743-748.

48. Lin, J.; Penchev, M.; Wang, G.; Paul, R.K.; Zhong, J.; Jing, X.; Ozkan, M.; Ozkan, C.S. Heterogeneous graphene nanostructures: $\mathrm{ZnO}$ nanostructures grown on large-area graphene layers. Small 2010, 6, 2448-2452. [CrossRef] [PubMed]

49. Fan, L.-Z.; Liu, J.-L.; Ud-Din, R.; Yan, X.; Qu, X. The effect of reduction time on the surface functional groups and supercapacitive performance of graphene nanosheets. Carbon 2012, 50, 3724-3730. [CrossRef]

50. Larionova, T.; Koltsova, T.S.; Kozlova, M.; Levitskii, V.S.; Eliseyev, I.; Smirnov, A.; Davydov, V.; Tolochko, O. Complex XPS and Raman Study of Graphene on Copper and Si/SiO2 Subjected to Ar Ion Treatment. Key Eng. Mater. 2016, 721, 258-262. [CrossRef]

51. Gawlik, G.; Ciepielewski, P.; Jacek, B. Study of Implantation Defects in CVD Graphene by Optical and Electrical Methods. Appl. Sci. 2019, 9, 544. [CrossRef] 